\title{
Expression and significance of estrogen receptor and progesterone receptor in endometrial tissue of patients with intrauterine adhesions
}

\author{
Jing $\mathrm{Ge}^{1}$, Yiwen Chen ${ }^{1}$, Hui Yang ${ }^{2}$, Jingxue Zhao ${ }^{1}$, Dongyan $\operatorname{Ren}^{1}$, Xiaomei $\mathrm{Wu}^{1}$ \\ ${ }^{1}$ Department of Gynecology, The First People's Hospital of Yunnan Province and Affiliated Hospital of Kunming University of Science and \\ Technology, Kunming, China; ${ }^{2}$ Department of Pathology, The First People's Hospital of Yunnan Province and Affiliated Hospital of Kunming \\ University of Science and Technology, Kunming, China. \\ Contributions: (I) Conception and design: J Ge; (II) Administrative support: None; (III) Provision of study materials or patients: H Yang, D Ren; \\ (IV) Collection and assembly of data: Y Chen; (V) Data analysis and interpretation: J Zhao, X Wu; (VI) Manuscript writing: All authors; (VII) Final \\ approval of manuscript: All authors. \\ Correspondence to: Xiaomei Wu. Department of Gynecology, The First People's Hospital of Yunnan Province and Affiliated Hospital of Kunming \\ University of Science and Technology, Kunming, China. Email: w_xiaomei@163.com.
}

\begin{abstract}
Background: Our study aims to analyze the expression and significance of estrogen receptor (ER) and progesterone receptor (PR) in endometrial tissues of patients with intrauterine adhesion (IUA).

Methods: Fifty-four patients with IUAs examined in our hospital from January 2017 to January 2019 were selected as the research object (observation group), 54 healthy women who had physical examinations during the same period were selected as the control group, and the immunohistochemical EnVision was used. Twostep and real-time fluorescent quantitative PCR methods were used to detect the expression levels of ER and PR in the endometrial tissues of the two groups of subjects.
\end{abstract}

Results: The immunohistochemical test results showed that ER's expression level in the observation group was significantly higher than that in the control group, and the difference between the two groups was statistically significant $(\mathrm{P}<0.05)$. The difference in $\mathrm{PR}$ expression levels between the two groups was insignificant $(\mathrm{P}<0.05)$. Real-time fluorescent quantitative PCR results showed ER and PR's expression levels in the observation group were significantly higher than those in the control group, and the difference between the two groups was statistically significant $(\mathrm{P}<0.05)$.

Conclusions: After IUA can detect ER and PR expression, we can formulate a personalized hormone treatment plan to improve the clinical treatment effect.

Keywords: Estrogen receptor (ER); progesterone receptor (PR); intrauterine adhesion (IUA); immunohistochemistry

Submitted Mar 22, 2021. Accepted for publication Apr 20, 2021.

doi: $10.21037 / g s-21-232$

View this article at: http://dx.doi.org/10.21037/gs-21-232

\section{Introduction}

Intrauterine adhesion (IUA) is usually caused by an endometrial injury caused by uterine surgery or infection of the uterine cavity, and abnormal repair of the uterus leads to uterine scars or adhesions (1). IUA patients often visit a doctor with reduced menstrual flow or amenorrhea, recurring lower abdominal pain, infertility, and repeated spontaneous abortions. Follow-up on medical history, patients often has a history of miscarriage or uterine cavity operation for other reasons. In recent years, the incidence of IUA has been increasing. On the one hand, it may be related to the increase in abortion caused by changes in sexual concepts, and whereas it is related to the improvement of people's medical conditions, the 
advancement of medical standards, and the wide application of hysteroscope diagnosis and treatment in clinical practice (2). There are also many studies and reports on the long-term birth outcomes of IUA patients. IUA patients are at risk of serious obstetric complications, including placenta previa, placenta accreta, fetal growth restriction, and fetal intrauterine developmental abnormalities, compared with no history of IUA. The risk of pregnant women has increased significantly, which seriously endangers women's reproductive health and mental health. It has also attracted increased attention from obstetricians and gynecologists. The exploration of its prevention and treatment methods has also become the research focus in gynecology in recent years (3).

At this stage, IUAs' clinical treatment is combined with uterine adhesion separation and postoperative administration of estrogen and progesterone to promote endometrial growth primarily (4). Oral estrogen preparations including estradiol valerate are commonly used. The main principle is estrogen can promote endometrial hyperplasia and speed up the epithelialization of exposed areas. Studies have shown that high-dose estrogen (estradiol valerate $8.12 \mathrm{mg} / \mathrm{d}$ ) after moderate and severe IUA has a significant preventive effect on the re-formation of IUA (5). At present, research on the principle of estrogen to improve the outcome of IUA treatment focuses on the changes of intracellular and extracellular factors, increasing vascular endothelial growth factor (VEGF), platelet-derived growth factor (PDGF), and epidermal growth factor. The expression of growth factors (epidermal growth factor, EGF), etc., increasing the formation of endometrial microvessels, promoting the proliferation of glands and stromal cells. These growth factors increase fibrinolytic enzymes' expression, including matrix metalloprotemases-9 (matrix metalloprotemases-9), to reduce fibrosis formation. An increase in the microvessel density (MVD) under the microscope promotes vascular opening and relaxation and promotes intimal regeneration and functional recovery $(6,7)$. However, some scholars believe that high blood estrogen levels can increase serum transforming growth factor- $\beta$ (TGF- $\beta$ ) and basic fibroblast growth factor (bFGF) levels, which promote the occurrence of endometrial fibrosis and aggravate the formation of IUA (8). Therefore, estrogen's efficacy for IUAs is still controversial, especially for estrogen dosage; there is no consensus in the academic community. Sex hormones regulate cell proliferation and apoptosis through signal transduction through their receptor pathways.
The target organs' cells are the main expression sites of sex hormone receptors, which bind to the corresponding hormones and react specifically to form hormone-receptor complexes, allowing the hormones to exert their biological effects (9). Both ER and PR are expressed in the nucleus and the cell membrane; most are expressed in the nucleus.

At present, the receptor expression pathway in the nucleus has been studied more in the academic field. Studies have shown that when ER and PR's content is insufficient or the function is abnormal, it can affect the endometrium's growth (10). As there is no uniform standard for the dosage and time of estrogen and progesterone, there is considerable controversy. Therefore, this study selected 54 patients with IUAs examined in our hospital from January 2017 to January 2019 as the research objects to analyze the expression and significance of ER and PR in the endometrial tissue of patients with IUAs. We present the following article in accordance with the STROBE reporting checklist (available at http://dx.doi.org/10.21037/gs-21232).

\section{Methods}

\section{General information}

Fifty-four cases of IUA female patients examined by hysteroscopy (OLYMPUS, Japan) and surgically diagnosed in our hospital from January 2017 to January 2019 were selected as the research object (observation group). Age $21-37$ years old, with an average of $29.63 \pm 5.32$ years old; 18 cases were mild, 30 were moderate, and eight were severe. Fifty-four female patients who underwent hysteroscopy during the same period and had a history of uterine cavity operation were selected as the control group, aged 20 39 years old, with an average of $30.14 \pm 5.37$ years old. All procedures performed in this study involving human participants were in accordance with the Declaration of Helsinki (as revised in 2013). The study was approved by The First People's Hospital of Yunnan Province (No. YYLH028). The enrolled patients were informed and signed the consent form. There was no statistically significant difference in the data between the two groups $(\mathrm{P}>0.05)$, comparable to Table 1 .

Exclusion criteria: (I) hormone therapy using estrogen, progesterone, or gonadotropin-releasing hormone analogs recently; (II) IUD placed within the past three months; (III) uterine fibroids, intrauterine polyps, endometrial hyperplasia, and abnormal endometrial cases. The diagnosis 
Table 1 General information of patients

\begin{tabular}{lcccc}
\hline Variate & $\begin{array}{c}\text { Observation } \\
\text { group }(\mathrm{n}=54)\end{array}$ & $\begin{array}{c}\text { Control group } \\
(\mathrm{n}=54)\end{array}$ & $\mathrm{t} / \mathrm{F}$ & $\mathrm{P}$ \\
\hline Age & $29.63 \pm 5.32$ & $30.14 \pm 5.37$ & 0.496 & 0.621 \\
$\begin{array}{l}\text { Pregnancy times } \\
\text { Symptom }\end{array}$ & $1.37 \pm 0.98$ & $1.52 \pm 1.02$ & 0.779 & 0.438 \\
$\begin{array}{l}\text { Decreased } \\
\text { menstrual flow }\end{array}$ & 31 & & 0.895 & 0.336 \\
Amenorrhea & 23 & 25 & & \\
\hline
\end{tabular}

of IUA is from the diagnostic grading system set up by the American Fertility Society in 1988 (level I is mild, score 1-4 points, level II is moderate, $5-8$ points, level III is severe, 9-12 points).

\section{Experiment}

\section{Methods of obtaining materials}

The subjects were collected on an empty stomach before 9 a.m. to evaluate related sex hormones. There was no abnormality. According to the women's menstrual cycle changes, specimen collection was conducted in the early stage of endometrial hyperplasia. Patients in the observation group underwent hysteroscopy (transcervical resection of adhesions, TCRA), the uterine adhesion tissue and adjacent endometrium were obtained with ring electrodes. $0.5 \mathrm{~cm}^{2}$ endometrium was selected as the study specimen. In administering TCRA to patients, it is necessary to preserve the uterine anatomy and normal endometrial tissue as much as possible. In the control group, patients who were diagnosed with non-uterine adhesions by hysteroscopy and had a history of uterine cavity operations, including infertility, incarceration of the contraceptive device, and uterine mediastinum, were clamped on the thicker part of the uterine lining $20 \mathrm{mg}$ of endometrial tissue, which was used as a research specimen and sent to pathology for examination.

\section{Reagents and instruments}

The primary antibody uses ready-to-use rabbit antihuman monoclonal antibodies ER (SP1) and (SP2) from Fuzhou Maixin Biotechnology Co., Ltd., and the secondary antibody EnVision two-step immunohistochemical staining kit (DAKO, Denmark). Triaminomethane (Trizol) and primers (Invitrogen Company, USA); Reverse Transcription
Kit (Thermo Company, USA); QuantiFast SYBR Green PCR Kit (Qiagen Company, Germany). Hysteroscope, cold light source, display system, electro-resection main unit, and foreign body forceps are Japan OLYMPUS company's products. The qRT-PCR instrument is the American ABI Company. The spectrophotometer was purchased from Thermo Company, USA.1.2.3 Immunohistochemical staining.

Take the proper archive wax block, form $4 \mu \mathrm{m}$ thick slices, paste them, and place them in a $65{ }^{\circ} \mathrm{C}$ oven for 30 minutes for dewaxing and hydration. Take citrate buffer ( $\mathrm{pH}$ 6.0), high pressure for antigen retrieval, and rinse with phosphate-buffered saline solution (PBS) 3 times, $3 \mathrm{~min} /$ time. $3 \%$ hydrogen peroxide block endogenous oxidase, rinsed with PBS 3 times. Use EnVision's two-step method for regular sectioning. Add the primary antibody and incubate at room temperature for $60 \mathrm{~min}$. Rinse three times with PBS, add secondary antibody dropwise, and incubate at room temperature for $30 \mathrm{~min}$. The ER is incubated with a 1:200 primary antibody, and the PR is incubated with a 1:500 primary antibody. The night temperature is set to $4{ }^{\circ} \mathrm{C}$. After the primary antibody is removed, add the secondary antibody dropwise, and then use phosphorus. Rinse with acid-buffered saline solution three times, $3 \mathrm{~min} /$ time. Add DAB staining solution to develop color under dark conditions; after washing with plenty of water, use hematoxylin for light dyeing. After the second, washing returns to blue, dry, and finally sealed with neutral gum. In the control group, the primary antibody was incubated with phosphate instead, and brown particles were observed in the specimen's cells, representing positive staining.

\section{Observation indicators}

Observe the specific expression of estrogen receptor (ER) and progesterone by immunohistochemical method. Positive expression of immunohistochemical staining: brown, light yellow, or brown granular material appears in the nucleus. The pathological section was magnified 400 times under a light microscope, and 10 highmagnification visual fields were randomly selected for observation, and comprehensive evaluation was performed according to the number of positive cells and the intensity of staining. Place the completed section under a microscope to observe the positive signal, and according to the positive signal expression in the section, it is divided into three levels: weak, medium, and strong. Scoring standard: 0 points mean negative; 1 point means a weak signal, and 
the signal is light yellow; 2 points represent the medium intensity, and the signal is brown; 3 points represent the high intensity, and the signal is brown. Simultaneously, scores are from the percentage of positive cells: 1 point is $1-20 \%$ of positive cells; 2 points is $21-50 \%$ of positive cells; 3 points is $51-70 \%$ of positive cells; 4 Score is $71-$ $100 \%$ of positive cells. Finally, the results of the positive signal expression strength score and the positive cell percentage score are added and divided by 2 , as the total score for each case, where negative is $0-1$ points, weakly positive is $1-2$ points, and positive is $2-3$ points, strong positive is $3-4$ points. Total score $=($ staining positive score + positive cell percentage score) $/ 2$.

\section{Real-time fluorescence quantitative PCR of endometrial tissue}

Use real-time fluorescent quantitative PCR (qRT-PCR) technology to detect the expression of ER and PR: take $20 \mathrm{mg}$ of endometrial tissue after grinding with liquid nitrogen and add $1 \mathrm{~mL}$ of Trizol to lyse, mix with $0.2 \mathrm{~mL}$ of chloroform for full fusion, and keep at $4{ }^{\circ} \mathrm{C}$ centrifuge at 12,000 r/minutes for 15 minutes, take the supernatant, but the same amount of isopropanol for sedimentation, centrifuge for 10 minutes, in the same way, discard the supernatant, add ethanol to dehydration, centrifuge again, and extract tissue RNA. Measure OD260 and OD280, respectively, to calculate the concentration and purity of RNA samples. Add $20-50 \mu \mathrm{L}$ DEPC water to speed up the dissolution for 10 minutes at a temperature of $55{ }^{\circ} \mathrm{C}$. Store at $-80{ }^{\circ} \mathrm{C}$ after centrifugation. Take $1 \mathrm{ug}$ of it as a template, perform RT reaction under the conditions of $37{ }^{\circ} \mathrm{C} 15 \mathrm{~min}-85^{\circ} \mathrm{C} 5 \mathrm{~s}-4^{\circ} \mathrm{C}$, and synthesize cDNA. Fluorescence quantitative PCR reaction, take out 11 of the above reaction solution as a template for fluorescent quantification, internal reference-actin: forward 5'-GGGAAATCGTGCGTGACATTAAGG-3', reverse 5'-CAGGAAGGAAGGCTGGAAGAGTG-3'; ER forward: 5'-ATCCTACCAACCCTTCAGT-3', reverse: 5'-TCATCAGGATCTCTAGCCAG-3'; PR forward 5'-TGGAAGGGCAGCACAACTAC-3', reverse: 5'-GAGAGCAACAGCATCCAGTG-3'.

The reaction system is: 2 SYBR Green mixture $5 \mathrm{~L}$, forward primer $(10 \mathrm{~mol} / \mathrm{L})$ and reverse primer $(10 \mathrm{~mol} / \mathrm{L})$ each $1 \mathrm{~L}$, cDNA $1 \mathrm{~L}$, RNase Free water $2 \mathrm{~L}$, total $10 \mathrm{~L}$. Reaction conditions: pre-denaturation at $95{ }^{\circ} \mathrm{C}$ for $5 \mathrm{~min}$, $10 \mathrm{~s}$, annealing at $60^{\circ} \mathrm{C}$, and extension for $30 \mathrm{~s}, 40$ cycles. The quantitative analysis of PR and ER expression levels adopts the 2-Ct method, where Ct is the cycle threshold, and each specimen is repeated 2-3 times, and the average value is taken for statistics.

\section{Statistical analysis}

SPSS 22.0 statistical software was used for analysis. Quantitative data were expressed as $(\bar{x} \pm s)$, comparison between groups was expressed by $t$-test, and counted data was expressed by (n). Analysis of variance was used. $\mathrm{P}<0.05$ showed the difference was statistically significant.

\section{Results}

\section{Examples of hysteroscope pictures of patients with different diseases}

According to the American Fertility Association (AFS) scoring standard, the IUA group patients were scored according to the degree of uterine cavity occlusion, IUAs under the hysteroscope for the menstrual condition. One patient with severe, moderate, and mild IUA was selected, respectively.

Mirror picture as an example (Figure 1).

\section{The positive expression of ER and PR in different tissues of the patient's endometrium}

All patients have various levels of ER and PR expression in the endometrium. The positive rate of ER in the gland is $69.44 \%$, and the positive rate of ER in the endometrial stroma is $54.63 \%$. There are statistical differences in ERpositive expression between glands and stroma significance: The positive rate of $\mathrm{PR}$ in glands was $58.33 \%$, and the positive rate of $\mathrm{PR}$ in the intimal stroma was $42.59 \%$. There was a statistically significant difference in $\mathrm{PR}$ positive expression between glands and stroma $(\mathrm{P}<0.05$, Table 2).

\section{Comparison of the expression of ER and PR in the patient's endometrial tissue}

The immunohistochemical test showed that the expression level of ER in the observation group was significantly higher than the control group, and the difference was statistically significant $(\mathrm{P}<0.05)$; the expression of $\mathrm{PR}$ in the observation group was lower than the control group, but the difference was not statistically significant $(\mathrm{P}>0.05$, Table 3$)$. The positive staining of ER and PR in the observation group is in the nucleus, as shown in Figures 2 and 3. 

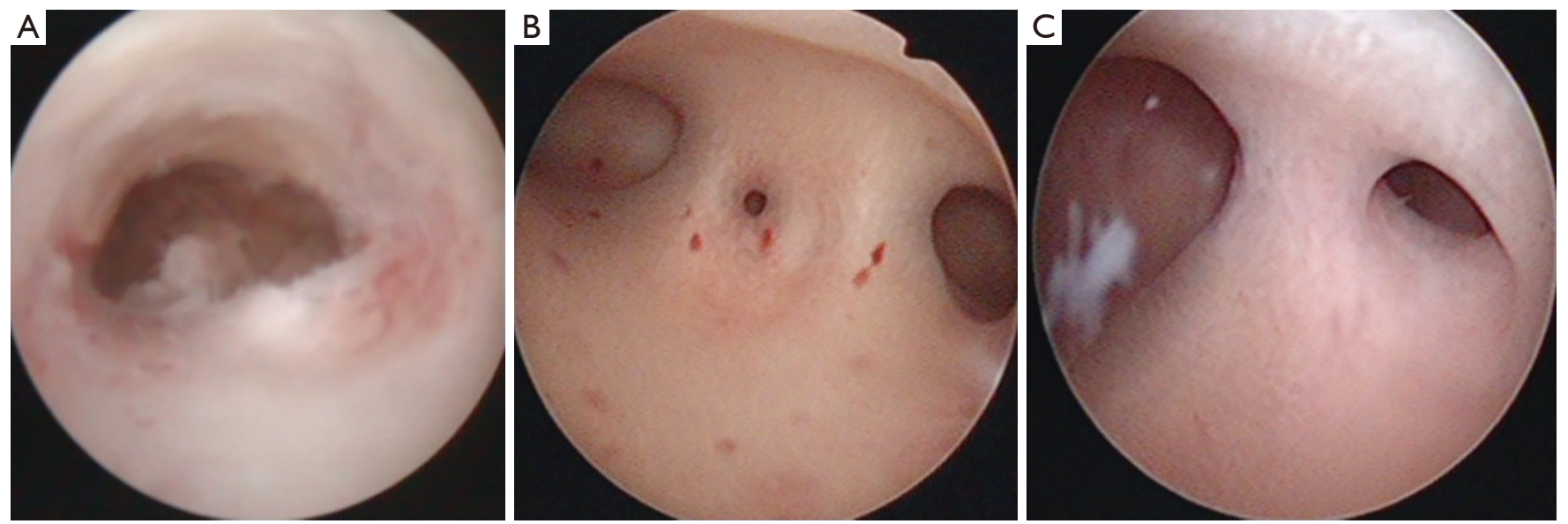

Figure 1 Hysteroscopy pictures of three cases of IUA with different disease levels. (A) Severe IUA patients; (B) moderate IUA patients; (C) mild IUA patients. IUA, intrauterine adhesions.

Table 2 The positive expression of ER and PR in endometrial tissue (n, \%)

\begin{tabular}{lcccc}
\hline Variate & $\begin{array}{c}\text { Endometrial } \\
\text { gland }\end{array}$ & $\begin{array}{c}\text { Intimal } \\
\text { stroma }\end{array}$ & F & P \\
\hline Total number of cases & 108 & 108 & - & - \\
ER & 33 & 49 & 1.596 & 0.035 \\
Negative (case) & 75 & 59 & & \\
Positive (case) & 69.44 & 54.63 & - & - \\
Positive rate (\%) & & & & \\
PR & 45 & 62 & 1.874 & 0.029 \\
Negative (example) & 63 & 46 & & \\
Positive (case) & 58.33 & 42.59 & - & - \\
Positive rate (\%) & & & & \\
\hline
\end{tabular}

ER, estrogen receptor; PR, progesterone receptor.

Table 3 Comparison of ER and PR expression levels between the two groups ( $\bar{x} \pm \mathrm{s}$, points)

\begin{tabular}{lcccc}
\hline Variate & $\begin{array}{c}\text { Observation } \\
\text { group }\end{array}$ & Control group & $t$ & $P$ \\
\hline Number of cases & 54 & 54 & - & - \\
ER & $3.59 \pm 0.69$ & $2.69 \pm 1.12$ & 3.42 & $<0.01$ \\
PR & $3.41 \pm 0.43$ & $3.55 \pm 0.32$ & 1.3 & $>0.05$ \\
\hline
\end{tabular}

ER, estrogen receptor; PR, progesterone receptor.

\section{Comparison of the expression levels of ER and PR in the two groups of patients detected by qRT-PCR}

Compared with the control group, the ER and PR protein expression levels of patients in the IUA group were higher, and the difference between the two groups was statistically significant $(\mathrm{P}<0.05$, Table 4).

\section{Discussion}

IUA refers to the type of uterine cavity disease caused by numerous factors that cause different degrees of damage to the endometrium's basal layer. At this stage, the clinical use of hysteroscopy and uterine adhesion separation combined with postoperative estrogen administration treatment promotes the endometrium to recover quickly (11). However, there are still controversies about the amount of estrogen and administration time.

It is reported in the literature that ovarian hormones directly affect the function of the endometrium, and estrogen is a key factor to promote the regeneration and repair of the endometrium and regulate menstruation (12). Progesterone is an important steroid hormone in the body, which interacts with estrogen and periodically acts on the endometrium $(13,14)$. ER and PR are important substances in the female endocrine system, both expressed in the uterus and highly expressed in the endometrium (15). ER 


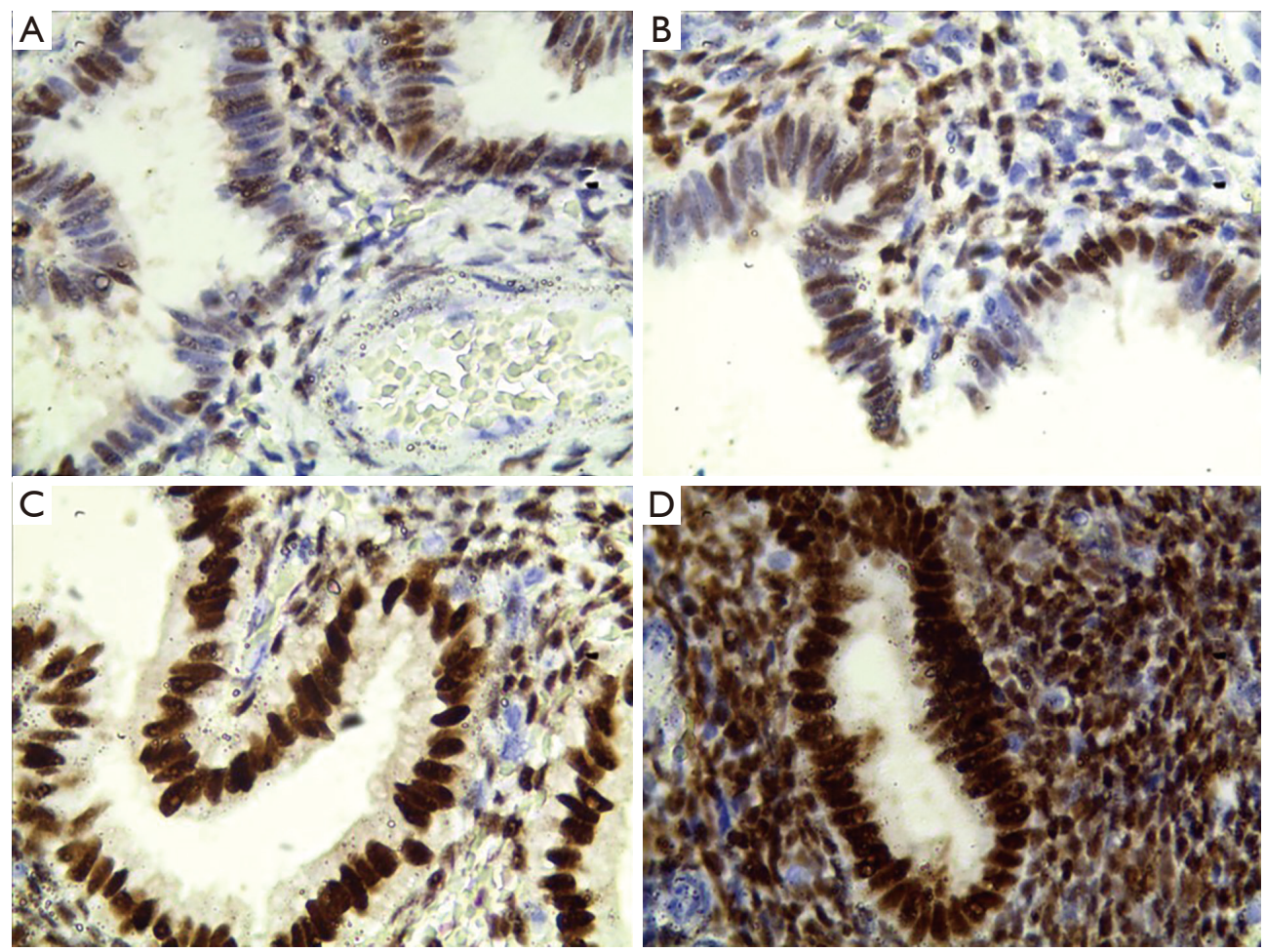

Figure 2 The expression of ER protein in endometrial tissue of IUA patients (400x). (A) Total score for immunohistochemical staining is 1.5 ; (B) total score for immunohistochemical staining is 2; (C) total score for immunohistochemical staining is 3; (D) total score for immunohistochemical staining is 4 points. IUA, intrauterine adhesions; ER, estrogen receptor.

and $\mathrm{PR}$ are in the nucleus. ER and PR can respectively recognize estrogen and progesterone with specific characteristics. When the receptor binds to the hormone to form a complex, it binds to the chromosome in an activated form, which causes gene activation and promotes, transcribes, and synthesizes new DNA, and then synthesizes new proteins, and promotes the growth and metabolism of endometrial cells through this type of proteins with biological functions $(16,17)$. ER is highly expressed in the endometrium's proliferative stage and low in the ovulation stage; PR is highly expressed in the ovulation stage, while it shows a downward trend in endometrial gland increases in endometrial stromal cells (18). The number and functional status of hormone receptors determine estrogen and progesterone's local level can exert biological effects. The body sex hormones of the related uterine cavity operators gradually decline. The lower expression levels of ER and PR lead to a significant decline in biological efficacy, which manifests as hypoxia in local tissues, changes in adhesion factors, and decreased angiogenesis.

The endometrium repairs the obstacle and finally causes the uterine cavity adhesion or the endometrial change.

Morphologically, the endometrium is divided into a functional layer and a basal layer. The functional layer is regulated by hormone levels and has periodic proliferation, secretion, and shedding characteristics. It is also the embryo implantation site; the basal layer regenerates after menstruation to form the functional endometrial layer. ER and PR are important ovarian sex hormones, highly expressed in the uterus, especially in the endometrium. This study showed that all patients had distinct levels of ER and PR expression in the endometrium. In glands, the positive rate of ER was $69.44 \%$, and the positive rate of PR was $58.33 \%$; the positive rate of ER in the endometrial stroma was $54.63 \%$, and the positive rate of PR rate was $42.59 \%$. The difference was statistically significant $(\mathrm{P}<0.05)$, and the expression of ER and PR was higher in the endometrial glands.

During a normal menstrual cycle, estrogen combines with ER to promote endometrial epithelium, glands, blood vessels, and stroma to show proliferative changes, repair, and reconstruction of the endometrium; Progesterone 


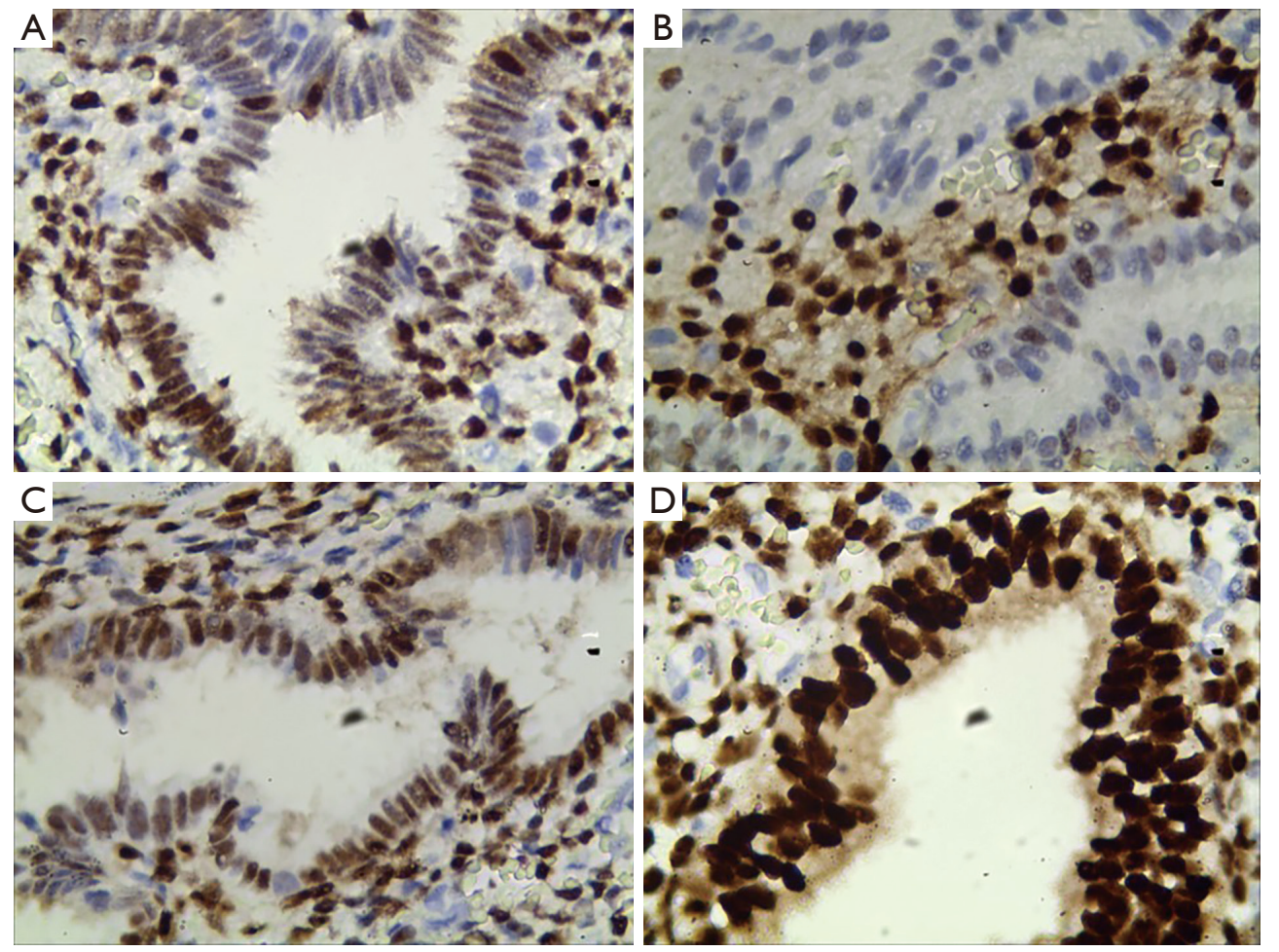

Figure 3 The expression of PR protein in IUA patients in endometrial tissue (400x). (A) Total score for immunohistochemical staining is 2 ; (B) total score for immunohistochemical staining is 1.5 ; (C) total score for immunohistochemical staining is 3; (D) total score for immunohistochemical staining is 4 points. IUA, intrauterine adhesions; PR, progesterone receptor.

Table 4 qRT-PCR detects the expression levels of ER and PR in the two groups of patients $(\bar{x} \pm s)$

\begin{tabular}{lcccc}
\hline Variate & $\begin{array}{c}\text { Observation } \\
\text { group }\end{array}$ & $\begin{array}{c}\text { Control } \\
\text { group }\end{array}$ & $t$ & $\mathrm{P}$ \\
\hline Number of cases $(\mathrm{n})$ & 54 & 54 & - & - \\
ER & $1.38 \pm 0.31$ & $0.97 \pm 0.12$ & 9.064 & $<0.01$ \\
PR & $1.15 \pm 0.19$ & $0.95 \pm 0.11$ & 6.694 & $<0.01$ \\
\hline
\end{tabular}

ER, estrogen receptor; PR, progesterone receptor.

combines with PR and cooperates with estrogen to continue to proliferate and transform the endometrium for the secretory period. This clinical study showed that compared with the control group, the ER protein expression level of patients in the IUA group using the immunohistochemistry method was significantly increased, and the difference was statistically significant $(\mathrm{P}<0.05)$; the $\mathrm{PR}$ protein expression level was low. The two groups were compared, the difference was not statistically significant $(\mathrm{P}>0.05)$; using real-time fluorescent quantitative PCR detection found that the ER and PR protein expression levels of patients in the IUA group were higher, and the difference between the two groups was statistically significant $(\mathrm{P}<0.05)$. It is hypothesized that IUAs are related to the high expression of ER and PR related. After the endometrium's basal layer is damaged or destroyed, blood vessel repair is impaired, and estrogen and progesterone's response is defective. The endometrium, epithelium, glands, blood vessels, and interstitial cells lack sufficient estrogen response, leading to hormones and receptors. The binding of protein is reduced, and estrogen and progesterone cannot be used to repair the inner membrane, and the membrane in the proliferative phase is transformed into the secretory membrane. Therefore, it is necessary to use a considerable amount of estrogen in clinical work to bind a considerable amount of free receptor protein to promote the growth and repair of the endometrium, improve the fibrous scar at the uterine cavity adhesion, and restore the patient's uterine cavity shape, menstruation, and pregnancy status. In clinical patients with mild to moderate IUAs, there is still part of the normal endometrium. Therefore, it is necessary to give 
the hysteroscope combined with hormone therapy after hysteroscopic IUA to promote endometrial regeneration. However, for severe IUAs, the endometrium's basal layer in patients with adhesions is damaged, and the endometrial blood vessels are repaired, resulting in insufficient estrogen response. Therefore, it is necessary to administer large doses of estrogen after using descending IUAs to promote endometrial growth-effective hormone concentration.

In summary, because ER and PR are crucial factors that affect the endometrium, IUA patients can first detect ER and PR expression after a hysteroscopy to plan personalized hormone treatment plans to improve clinical treatment effects.

\section{Acknowledgments}

Funding: None.

\section{Footnote}

Reporting Checklist: The authors have completed the STROBE reporting checklist. Available at http://dx.doi. org/10.21037/gs-21-232

Data Sharing Statement: Available at http://dx.doi. org/10.21037/gs-21-232

Conflicts of Interest: All authors have completed the ICMJE uniform disclosure form (available at http://dx.doi. org/10.21037/gs-21-232). The authors have no conflicts of interest to declare.

Ethical Statement: The authors are accountable for all aspects of the work in ensuring that questions related to the accuracy or integrity of any part of the work are appropriately investigated and resolved. All procedures performed in this study involving human participants were in accordance with the Declaration of Helsinki (as revised in 2013). The study was approved by The First People's Hospital of Yunnan Province (No. YYLH028). The enrolled patients were informed and signed the consent form.

Open Access Statement: This is an Open Access article distributed in accordance with the Creative Commons Attribution-NonCommercial-NoDerivs 4.0 International License (CC BY-NC-ND 4.0), which permits the noncommercial replication and distribution of the article with the strict proviso that no changes or edits are made and the original work is properly cited (including links to both the formal publication through the relevant DOI and the license). See: https://creativecommons.org/licenses/by-nc-nd/4.0/.

\section{References}

1. Healy MW, Schexnayder B, Connell MT, et al. Intrauterine adhesion prevention after hysteroscopy: a systematic review and meta-analysis. Am J Obstet Gynecol 2016;215:267-75.e7.

2. Dreisler E, Kjer JJ. Asherman's syndrome: current perspectives on diagnosis and management. Int $\mathbf{J}$ Womens Health 2019;11:191-8.

3. Salazar CA, Isaacson K, Morris S. A comprehensive review of Asherman's syndrome: causes, symptoms and treatment options. Curr Opin Obstet Gynecol 2017;29:249-56.

4. Khan Z, Goldberg JM. Hysteroscopic Management of Asherman's Syndrome. J Minim Invasive Gynecol 2018;25:218-28.

5. Liu AZ, Zhao HG, Gao Y, et al. Effectiveness of estrogen treatment before transcervical resection of adhesions on moderate and severe uterine adhesion patients. Gynecol Endocrinol 2016;32:737-40.

6. Zhou WJ, Zhang J, Yang HL, et al. Estrogen inhibits autophagy and promotes growth of endometrial cancer by promoting glutamine metabolism. Cell Commun Signal 2019;17:99.

7. Chantalat E, Valera MC, Vaysse C, et al. Estrogen Receptors and Endometriosis. Int J Mol Sci 2020;21:2815.

8. Smith LC, Moreno S, Robinson S, et al. Multi-walled carbon nanotubes inhibit estrogen receptor expression in vivo and in vitro through transforming growth factor beta1. NanoImpact 2019;14:100152.

9. Gompel A. Progesterone and endometrial cancer. Best Pract Res Clin Obstet Gynaecol 2020;69:95-107.

10. Marquardt RM, Kim TH, Shin JH, et al. Progesterone and Estrogen Signaling in the Endometrium: What Goes Wrong in Endometriosis? Int J Mol Sci 2019;20:3822.

11. Kou L, Jiang X, Xiao S, et al. Therapeutic options and drug delivery strategies for the prevention of intrauterine adhesions. J Control Release 2020;318:25-37.

12. Rodriguez AC, Blanchard Z, Maurer KA, et al. Estrogen Signaling in Endometrial Cancer: a Key Oncogenic Pathway with Several Open Questions. Horm Cancer 2019;10:51-63.

13. Patel BG, Rudnicki M, Yu J, et al. Progesterone resistance in endometriosis: origins, consequences and interventions. 
Acta Obstet Gynecol Scand 2017;96:623-32.

14. Szukiewicz D, Stangret A, Ruiz-Ruiz C, et al.

Estrogen- and Progesterone (P4)-Mediated Epigenetic Modifications of Endometrial Stromal Cells (EnSCs) and/or Mesenchymal Stem/Stromal Cells (MSCs) in the Etiopathogenesis of Endometriosis. Stem Cell Rev Rep 2021. [Epub ahead of print]. doi: 10.1007/s12015-02010115-5.

15. Wang C, Tran DA, Fu MZ, et al. Estrogen Receptor, Progesterone Receptor, and HER2 Receptor Markers in Endometrial Cancer. J Cancer 2020;11:1693-701.

16. Klonos E, Katopodis P, Karteris E, et al. Endometrial changes in estrogen and progesterone receptor expression during implantation in an oocyte donation program. Exp Ther Med 2020;20:178.

17. Chi RA, Wang T, Adams N, et al. Human Endometrial Transcriptome and Progesterone Receptor Cistrome Reveal Important Pathways and Epithelial Regulators. J Clin Endocrinol Metab 2020;105:e1419-39.

18. Nisar M, Mushtaq S, Hassan U, et al. Androgen Receptor Expression In Endometrial Carcinoma And Its Correlation With Estrogen Receptor And Progesterone Receptor And Clinicopathological Findings. J Ayub Med Coll Abbottabad 2020;32:160-4.

(English Language Editor: J. Chapnick)
Cite this article as: Ge J, Chen Y, Yang H, Zhao J, Ren D, $\mathrm{Wu} \mathrm{X}$. Expression and significance of estrogen receptor and progesterone receptor in endometrial tissue of patients with intrauterine adhesions. Gland Surg 2021;10(4):1478-1486. doi: $10.21037 / g s-21-232$ 